\title{
The Use of Mobile Phone in English Language Lesson: A Shift from Teacher-Centred to Student-Centred through Mobile Learning
}

\author{
Mozes Kurniawan ${ }^{1, *}$ \\ ${ }^{1}$ Universitas Kristen Satya Wacana, Faculty of Teacher Training and Education, Indonesia
}

\begin{abstract}
Most area of life requires changes. One of the things changes from time to time is learning method or strategy. In educational sector, especially in Teaching English to Speaker of Other Language (TESOL), teachers are demanded to have creative and innovative ways to teach language other than their own mother tongue in order to maintain pupils' interest, creativity and learning outcomes. One alternative way to teach English is by integrating technology particularly mobile phone. However, there still questions on what is going on if teachers allow student to access mobile phone during class and how it can be done. This study aims to enrich teachers' knowledge and broaden the paradigm of using mobile learning method serving the digital native generation in TESOL. A reflective analysis was done in collaboration with literature support to provide a clear image of mobile learning done in English class at a particular study program of Universitas Kristen Satya Wacana, Indonesia. The result showed that students' need a transformation of teaching learning process, students can be engaged more actively on learning by using mobile phone and some possible activities are proposed for supporting studentcentred instruction.
\end{abstract}

\section{Introduction}

Many people considered as modern citizen in this global era are agree with statement mentioning that English is an international language and is important to be mastered [1]. One of countries who believes in that statement is Indonesia. Recently, Indonesia have been a part of ASEAN Economic Community meaning that its people should have an additional competence called English language proficiency for English is a global language used by many countries in the world and one of requirements for people to compete [2].

The importance of English in this modern era seems to encounter problems. Some said that the problems come from the learning materials and subject knowledge (curriculum) while some others said it was because of teacher's lack of instructional approach, strategy and technique (pedagogy) [3]. Perceiving those issues, practitioners as well as common people might have various perspective and reactions. However, one of perspectives which

*Corresponding author: mailbox.mozeskurniawan@gmail.com 
is better to describe is by using analogy of Walt Disney's story in 'Alice through The Looking Glass'. The main character, Alice, was demanded to borrow a tool which could be used to travel back time and save her friend named Hatter, a hat maker. Due to her kindness and love to Hatter, Alice went to a castle owned by Time, the personification of time itself and begged to borrow the tool. In a brief, she took the tool without permission and was commanded to put it back to its place since she cannot change the past. Time who taught her strictly without any gentleness and innovation did not attract her attention. Alice travelled back time and changed nothing but she learned something valuable from the trip. Finally, she realised that what Time said was right and she got valuable things to learn by experiencing rather than listening to Time's prohibition.

This story represents educational problems happening in recent years, i.e. pupils tent to ignore classroom lesson, teacher's lecture and instruction by arguing that they get bored by the materials given and the way teacher conduct the lesson. Pupils cannot develop their English proficiency since the curriculum and pedagogy match nothing to their needs and interest even it makes them frustrated. The old-fashioned English teaching where teacher standing in front of class, lecturing and giving instruction resists their motivation to learn [4]. Furthermore, improper material design in teaching English contributes to the problems. If there is no way out for the problems, there will be a stagnancy of Indonesian people's English proficiency and Indonesia will suffer a big lost in this global era.

On regard to the problems, there appears an idea of using mobile phone in English language learning, a.k.a. mobile learning. This method has caught researchers' attention for years and become a fresh alternative to conquer problems particularly in English language education although practitioners still have questions on how the implementation will be. Therefore, this study aims to enrich teachers' knowledge and broaden the paradigm by presenting perspectives, real practice and reflective analysis on the use of mobile learning method serving the digital native generation in Teaching English to Speaker of Other Language (TESOL).

\section{Literature Review}

\subsection{Perspectives on English Language in Indonesia}

English as mentioned previously is perceived as a widespread language used by people all over the world. Due to its importance, many people among countries urge to learn and master English in order to get positive chances. Since English can be a good medium to communicate, teach subject knowledge in higher education and enhance social status, many countries have tried to develop their curriculum by adding English as one required subject or just a compulsory one.

Indonesia did similar action responding to the popularity of English in this modern era. English was considered as the most important and significant foreign language in Indonesia around 1980s and, starting from that time, English grew quickly from 1990s ahead. It was also determined as one of subjects taught in formal schools based on the national curriculum of Indonesia [5].

For Indonesia, English is a foreign language which enables its speakers to shape their identity to be a global citizen or join international community. In a simpler way, someone is considered as a part of Indonesia when the one is able to communicate in Indonesian language and internalize it as a part of his/her daily life. The same concept applies for English language. Indonesian people are recognised as global citizen, for example in ASEAN Economic Community, when they are able to communicate and interact to people in the same community. It will be possible if Indonesian people have proficiency in using 
English. Thus, language, especially English, is not only functioned as medium of communication but also an identity shaper to have broaden connection and chances [6].

By considering those ideas that English, nowadays, becomes crucial for Indonesian people in order to compete and take benefits from global opportunities, people are looking for effective English education since no language is sufficient to aid communication and open the opportunities among countries [7]. Even though English had been introduced in educational setting for decades ago and believed as important language to master, its implementation in Indonesia is still out of expectation. Researchers found that English in Indonesia is still in a trouble such as teachers' way in delivering suitable English material, activities and assessment for Indonesian context need to be improved. Teacher are required to develop their basic English knowledge for being effective English as a Foreign Language (EFL) teachers. In other words, teachers should develop and/or innovate effective and even creative method so that pupils are motivated to learn English full-heartedly [8].

Besides, the matter of large number of pupils in class that need to be managed and put attention on, conventional way of teaching where teacher is standing in front of class lecturing and less availability of instructional media also become point to stress [9]. Those problems lead to an unconscious teaching learning process called by Teacher-Centred Learning where teacher is the main focus while students are less dominant and tent to be passive rather than Student-Centred Learning where students are the focus of learning which are permitted to design, innovate and develop an attractive leaning atmosphere.

\subsection{Teacher-Centred vs. Student-Centred Learning}

Teacher-Centred Learning (TCL) is an instructional approach which puts teacher at the centre of learning process such as: teacher leads the learning process, prepare for activities, becomes source of knowledge and make the determination in classroom activities [10]. TCL is believed to make pupils more passive for just listening and writing teacher's speech and instruction. TCL has some characteristics as follows: 1) Teacher is the sole of direction and control, 2) Teacher makes the rule to be followed, 3) Tasks and responsibility owned by teacher [11], 4) Teacher passes the knowledge and information to students, and 5) Teaching and assessment are two separate entities done by scored test system [12]. This approach is perceived to be problematic particularly in EFL since pupils' innovation and interest are hindered.

The other strategy which have been caught as a flexible and fresh to meet pupils' needs and wants is Student-Centred Learning (SCL). SCL is clearly defined as instructional approach focused more on shifting students' passive role to active role in discussion, curiosity and participation. SCL places students in the centre of teaching learning process while developing personal learning skill, knowledge, critical thinking and reflective thinking [13]. SCL characteristics are including 1) The responsibility of learning is delegated to students, 2) Topics are constructed relevantly for learners, 3) Learners are encouraged to engage to real learning experience, 4) The collaboration between learners is enhanced, and 5) There is a shift from teacher's function as learning resource [14].

Recently, there are a great change from TCL to SCL since the characteristics are best suit to English language lesson from preparing appropriate materials, conducting active learning and assess students' development through their performance. Nonetheless, teachers still get confused and trapped on how SCL can be conducted in innovative ways. Researchers proposed an alternative adopting SCL approach through familiar technology, mobile phone. Later on, mobile phone-based learning process is called by mobile learning. 


\subsection{Mobile Learning in Education}

Mobile learning (M-Learning) defines as a process to get information and knowledge through interactive learning environment with multiple contexts using a portable technology called by mobile phone. M-Learning serves learners by using personal gadgets namely smartphone, personal digital assistant (PDA), tablet and similar technologies [15].

M-Learning is characterized by having accessibility where students are free and easy to access learning material; immediacy where students do not need to wait for long just to have/generate learning materials and tasks; interactivity that encourage students to engage in discussion based on the lesson [16], flexibility that gives students wider option of technologies to be used in accessing learning material; and mobility where students are permitted to learn anytime and anywhere.

English materials that previously perceived as something difficult to learn especially those whose first language is not English might be reduced and even solved by integrating technology through M-Learning. Various type of technology was believed changing teacher's way of teaching. It also reported as a successful way to help students develop their English proficiency from vocabulary mastery, grammar acquisition and some subjectspecific knowledge comprehension [17].

However, teachers still question and demand about detail exploration and explanation on how mobile phone or similar technologies are used in English language lesson and what kind of activities are possible to do with such technology. The following discussion reveals transformation in English curriculum and pedagogy, mobile learning for engaging students' participation and some possible mobile-based activities.

\section{Methods}

This was a qualitative study aiming to enrich teachers' knowledge and broaden the paradigm of using mobile learning method serving the digital native generation in TESOL. This qualitative study used reflective analysis in collaboration with literature review so that the substance of this research was presented empirically based on real practices. The main data were 6 international journals discussing mobile learning in English education from 2012 up to 2017. The data complementary was gained from reflection of real experience on English language education course conducted in Faculty of Teacher Training and Education of Universitas Kristen Satya Wacana, Indonesia.

\section{Discussion}

\subsection{Transforming English Curriculum and Pedagogy through $M$-Learning}

Based on 6 international journals analysing about the use of mobile learning in English language education, there were changes of former instructional material and method. Researchers found that English required its speaker to learn large amount of vocabulary, pupils did not only learn new words but also the relation among words, and there were various learning style in learning English that should be accommodated wisely. Those challenges brought pupils to difficulty and anxiety [18]. The action showed in journal 2017 (Indonesia) was changing students' vocabulary learning through mobile application and content while pupils build their learning style that fits to their needs.

Another point of view from journal 2015 (Ethiopia) revealed that English education might encounter classroom limitation in conducting learning activities and improper context while demanding students to demonstrate language features. Those challenge let to 
the shift of conventional teaching learning process to mobile-assisted English learning. The result was that utilizing mobile devices could promote interaction during learning process and situate learning based on intended context and purpose. It also brought advantages such as: portability and connectivity where students can access the learning material inside and outside classroom.

In addition, journal 2016 (Saudi Arabia) and 2012 (USA) found English language learning problem such as: English taught in traditional-based classroom (face-to-face) lessen students' vocabulary retaintion and engagement. Students also tent to avoid physical labour namely visiting library and borrowing books [19]. By integrating iPad in classroom task and submission of works, students were attracted and committed to engage and collaborate in a boundless access. Moreover, the use of M-Learning improved students' English writing skill, new words and spelling knowledge and helped them translating words as well as saving learning resource immediately.

Furthermore, journal 2013 (USA) and 2014 (Hong Kong) mentioned that there were activities done by using small mobile device such as: communicating to family, shopping, mapping, finding a good living but less of them used it to improve learning in their education [20]. There were also teachers who resist to change their teaching and learning process with new technology since it was not perceived as part of learning culture. To have a better change, the researchers implemented mobile technology in English education and found some eye-catching changes. There were a large number of positive views toward the use of M-Learning particularly that it increased access to resources, improved communication with teachers and classmates, and was convenient in using time effectively.

\subsection{Some Possible Mobile-Based Activities in English Lesson}

At the beginning, there was question asking on how to use mobile devices or similar technology in English language lesson. Based on the analysis of 6 international journals, there were some suggestion in applying mobile learning in English lesson.

\subsubsection{Instant Messaging Application for Vocabulary and Grammar Training}

Vocabulary and grammar were developed by using instant messaging such as: BlackBerry Messenger, WhatsApp, LINE and others. The mechanism was just preparing topic and/or instruction that students need to do then chose one media as the medium. Students did discussion, works and/or tasks through the chosen media and built their habit of using English by such instant messaging. The result showed that students learn more new English vocabulary and simple pattern. The point is habituating pupils in using English as frequently as possible. Pupils have gradually been engaged in English lesson by using instant messaginng application more frequently.

\subsubsection{Mobile Device for Virtual Sharing and Engagement}

As previously stated about connectivity, interactivity and immediate access, teachers might use mobile learning through its virtual access namely: E-mail, Dropbox, Google Drive, e-Portfolio and so on to enlarge students' access to resources and teacher-students' distant interaction. The researcher used this way to provide English instructional module prior to course schedule in order to be learnt. In class, where students have accessed given module, discussion seemed to be more alive without pause and repetition on topic discussed. The flow of discussion and brainstorming went smoothly. Students admitted that file sharing and teacher-students' contact prior to course schedule helped them a lot. It built engagement between teacher and students as well as the material prior to class meeting. 


\subsubsection{Video Application for Practicing Speaking \& Communication}

The most interesting part of mobile device was multimedia feature. These included YouTube, Recorder, audio video application such as: HOOQ, Netflix and other similar tools. Naturally, students frequently accessed those tools for their own sake and got something to learn from what they did in pleasure. In researcher's English course, students were demanded to watch instructional videos days before the lesson. They watched how to teach English to children, how to pronounce a string of words in a certain topic and how to deal with interlocutors. Those videos might be a model for them to imitate and inspire a new insight. Most of them learnt to speak well by following the ideal flow of speaking, pronounce difficult words correctly and practice communication with classmates.

\section{Conclusion}

To sum up the result of this reflective analysis, there are three things highlighted. First, researcher and English language practitioners should be aware that technology in this case mobile devices are very close to students' life and can be utilize to enhance English language learning effectively. Then, to provide students with an interesting, innovative and engaging English language learning, teachers need to consider transformation of their learning method by integrating mobile technology in English lesson since it benefits students as well as teachers to have a meaningful teaching learning process. The last but not least, there are some possible English language tasks and activities which utilize mobile devices to have a fresh and creative learning atmosphere resulting to the improvement of English proficiency namely vocabulary, grammar, speaking and development of instructional management such as file sharing, resources accessibility and connectivity.

\section{References}

1. M. Lak, H. Soleimani, F. Parvaneh. J. Adv. in ELT. 5, 1 (2017)

2. F. Copland, S. Garton, A. Burns. TESOL Q. 48, 738 (2013)

3. P. Goss, J. Sonnemann. G. I. R. 01, 6 (2017)

4. M. Kurniawan. Prodi PBI FBS UKSW. 24 (2013)

5. S.S. Mappiasse, A.J.B. Sihes. ELT. 7, 113 (2014)

6. S.S. Sukandi. ICLLCE. 24 (2015)

7. B.P. Sinha. TC: Int'1. J. in En. 2, 1 (2011)

8. H. Wati. IJI. 4, 79 (2011)

9. Abid, P. Mercieca, T. Dobinson. TACLL. (2015)

10. O.A.S. Idris. AJER. 4, 1317 (2016)

11. T. Garret. JCI. 43, 34 (2008)

12. S. Rafi. M.Phill. Edu. (2015)

13. B. McCombs, J.S. Whistler. The Learner-Centered Classroom and School: Strategies for Increasing Student Motivation and Achievement. J-B Publish. CA. (1997)

14. S. Hodge. Occa. Paper on Learn. \& Teach UniSA. 3, 1 (2010)

15. M. M. Bachore. J. Edu. Pratc. 6, 50 (2015)

16. J.P. Rossing, W.M. Miller, A.K. Cecil, S.E. Stamper. JSTL. 12, 1 (2012)

17. H. Cahyani, B.Y. Cahyono. TEFLIN J. 23, 130 (2012) 
18. M. Kurniawan. ASIAN EFL J. 8, 155 (2017)

19. G.M. Nalliveettil, T.H.K Alenazi. JLTR, 7, 264 (2016)

20. D. Kin, D. Rueckert, D.J. Kim, D. Seo. J. Lang. Learn. Tech., 17, 52 (2013) 